\title{
Functional Change of Brain Serotonergic Activity and Free Tryptophan in the Plasma of Depressed Women
}

\author{
Felipe Vázquez-Estupiñan', Rocío Herrera-Márquez¹, José Antonio Mondragón-Herrera1, \\ Guillermina Lara-Pérez ${ }^{1}$, Gabriel Manjarrez-Gutiérrez ${ }^{1,2 *}$ \\ ${ }^{1}$ Laboratory of Molecular Pathology, Cardiology Hospital, National Medical Center (CMN-SXXI), Mexican Institute of Social \\ Security (IMSS), Mexico City, Mexico \\ ${ }^{2}$ Medical Research Unit in Neurological Diseases, Specialties Hospital, CMN-SXXI, IMSS, Mexico City, Mexico \\ Email: *willisga@prodigy.net.mx, *gmanjarrezg@gmail.com
}

How to cite this paper: Vázquez-Estupiñan, F., Herrera-Márquez, R., Mondragón-Herrera, J. A., Lara-Pérez, G., \& Manjarrez-Gutiérrez, G. (2019). Functional Change of Brain Serotonergic Activity and Free Tryptophan in the Plasma of Depressed Women. Open Journal of Depression, 8, 5-15.

https://doi.org/10.4236/ojd.2019.81002

Received: December 5, 2018

Accepted: January 14, 2019

Published: January 17, 2019

Copyright $\odot 2019$ by author(s) and Scientific Research Publishing Inc. This work is licensed under the Creative Commons Attribution International License (CC BY 4.0).

http://creativecommons.org/licenses/by/4.0/

\begin{abstract}
The main objective was to show the decrement of serotoninergic brain activity in depressed women, through the analyses of the slope amplitude of N1/P2 components of the auditory-evoked potentials (AEP), and the measurement of the L-tryptophan free fraction in plasma (FFT). This cross-sectional study was carried out in 60 women, 30 depressed and 30 normal controls. Both groups were measured FFT, glucose, and neutral amino acids (NAA) levels; besides performing AEP to analyses the N1/P2 slope amplitude. It was found a lengthening in the slope amplitude of N1/P2 components of AEP in the group of depressed women, and despite that the level of FFT was low, there were no changes between bound fraction and the total L-Trp. The former suggests a decrease in serotonergic brain activity in the group of depressed women. Otherwise, since the auditory cortex response to sound is regulated by serotonergic innervation, it was expected a change in the behavior of AEP in the group of depressed patients. Thus, the slope amplitude of N1/P2 components of the AEP and the measurement of FFT have proved to be a good clinical indicators of the serotonergic neurotransmission state in the brain of depressed patients, and in another clinical conditions where brain serotonin is involved.
\end{abstract}

\section{Keywords}

Depression, Auditory-Evoked Potential (N1/P2) Component, Brain, Serotonin, L-Tryptophan

\section{Introduction}

Depression triggers a strong impact on general population morbidity and leads 
to a high rate of disability worldwide (Kessler \& Bromet, 2013), taking into account that in Mexico, its prevalence reaches a $4.8 \%$ between the 18 and 65 years of age, only outweighed by anxiety disorders (Medina-Mora et al., 2005; Wagner et al., 2012; Berenzon et al., 2013). Notwithstanding its diagnosis is clinical and based on the parameters established by the Diagnostic and Statistical Manual of Mental Disorders of the American Psychiatric Association (DSM-IV) (American Psychiatric Association, 1994), the neurophysiopathologycal basis of depression has not yet been described. However, there are some hypotheses related to the dysfunction of some networks and neurotransmission neuronal systems inside the limbic area, and the cortex; which are based on different polymorphisms that may lead to metabolism dysfunction, and transport alterations of monoamines, serotonin, dopamine, norepinephrine, glutamate, and gamma-amino-butyric acid (GABA) along these systems (Nestler et al., 2002; Meltzer, 1990; Dunlop \& Nemeroff, 2007; Nutt, 2006; Sullivan et al., 2000; Lohoff, 2010; Pehrson \& Sanchez, 2014). Neurogenesis also influence the development of the disease (Jedynak et al., 2007), besides genetics, environment influence (Sullivan et al., 2000), and the role inflammation plays (McNally et al., 2008; Patel, 2013). Thus, depression must not be viewed as a single disease, but as a syndrome triggered by different causes and physiopathology (Nestler et al., 2002). Different attempts have been made to establish several subtypes of depression, based on certain groups of symptoms (Akiskal, 2000; Blazer, 2000); however, these subtypes are based solely on symptomatic differences, and there is as yet no evidence that they reflect different underlying disease states.

The scientific evidence of serotoninergic activity in the physiopathology of depression that has been reported in recent years, has led to the therapeutic use of selective serotonin reuptake inhibitors in the depressed patient (Mann, 1999; Gijsman et al., 2004; Margoob et al., 2008; Carr \& Lucki, 2011; Berhan \& Barker, 2014; Morrissette \& Stahl, 2014). Likewise, different pathophysiological changes have been reported, such as the decrease in the serotonin level inside the brainstem, and a decrease in 5-hydroxyindoleacetic acid in the cerebrospinal fluid; increased clearance of L-Trp during major depressive episodes, in contrast with a minor plasma level (Banki et al., 1981; Stanley et al., 1985; Ferrier et al., 1986); and changes in the expression of various serotonergic receptors (Carr \& Lucki, 2011; Nagayama et al., 1991; Stockmeier et al., 1997) along with an increased neuroendocrine activity (López et al., 1998; Parker et al., 2003).

This study is based on the hypothesis that sustains that depressed women have a significant decrease in brain serotonergic activity, which could be demonstrated through the analyses of the slope amplitude of N1/P2 components of the auditory-evoked potentials (AEP), and the measurement of the L-tryptophan free fraction in plasma (FFT) (Hegerl \& Juckel, 1993; Juckel et al., 1997; Manjarrez et al., 2001; Manjarrez et al., 2005a; Manjarrez et al., 2005b). Recent results show that patients with type 1 and type 2 diabetes (with or without depression) and patients who develop depression after myocardial infarction present a significantly higher slope of the amplitude/stimulus function (ASF) of the N1/P2 
component obtained at various intensities of the auditory stimuli, reflecting a low brain serotonergic activity (Manjarrez et al., 2006; Manjarrez et al., 2007; Manjarrez-Gutierrez et al., 2009; Manjarrez-Gutierrez et al., 2013). On the contrary, low-intensity dependence is assumed to result from high serotonergic function as observed in intrauterine growth-restricted infants and rats (Manjarrez et al., 2001; Manjarrez et al., 2005a). Therefore, the ASF slope of the N1/P2 component of IDAEPs and the free fraction of L-tryptophan (FFT) have been used as indicators of central serotonergic activity in humans (Manjarrez et al., 2005a; Manjarrez et al., 2006; Manjarrez et al., 2007; Manjarrez-Gutierrez et al., 2009; Manjarrez-Gutierrez et al., 2013).

\section{Patients and Methods}

This study was approved by the Research and Ethics Committees of the Specialties Hospital of the National Medical Center (IMSS, Mexico City). All women provided informed consent after receiving a detailed explanation of the involved procedures. A cross-sectional study was carried out in 60 women (aged 47 - 52 years). Two groups were formed. The first group included 30 patients with depression according to the DSM-IV criteria. None of the depressed patients' received specific treatment. They did not have neurological events, cardiovascular complications, or signs of brain or other psychiatric disorders. The use of medications such as sedatives, antidepressants or neuroleptics, were considered as an exclusion criterion. On the other hand, 30 normal women within a similar age range served as a control group. All patients in this study had normal hearing, with a perception up to $20 \mathrm{~dB}$ confirmed by an audiologist, and also normal cognitive functions. Patients consumed a regular diet (22-26/kcal/kg/day).

\section{AEPs Recording and Analysis}

During the recording of IDAEPs, each subject sat in a comfortable chair in an electrically shielded and sound-attenuated room, adjacent to the recording apparatus (Viking 4, Nicolet). IDAEPs were recorded with two channels referred to as $\mathrm{Cz}$. AgCl electrodes were used (EEG disk electrode NE-101, $10 \mathrm{~mm}$ diameter). It were applied two hundred clicks $(1.5 \mathrm{kHz}, 100 \mathrm{~ms}$ duration with $10 \mathrm{~ms}$ rise and $10 \mathrm{~ms}$ fall time, interstimulus interval between 1000 and $1500 \mathrm{~ms}$ ), with three intensities to assess the intensity dependence (70, 90 and $103 \mathrm{~dB}$ ). Each of the intensities was separately applied, binaurally in a sequential form through headphones. Data were collected with a sampling rate of $1000 \mathrm{~Hz}$ and an analogue bandpass filter $(0.1 \mathrm{~Hz}-150 \mathrm{~Hz})$. Prestimulus periods $(200 \mathrm{~ms})$ and poststimulus periods ( $500 \mathrm{~ms}$ ) were evaluated with 200 sweeps for each intensity increment. For artifact suppression, all trials were automatically excluded from averaging if the voltage exceeded $50 \mu \mathrm{V}$ in either of the two channels at any time during the averaging period. The X-Y graphs of the IDAEP were examined and prominent peaks identified and measured using specific software (Viking 4, Nicolet). Plots shown in Figure 1 are representative examples of IDAEP long latency waves obtained by sequential stimulations of 70,90 and $103 \mathrm{~dB}$ from a 


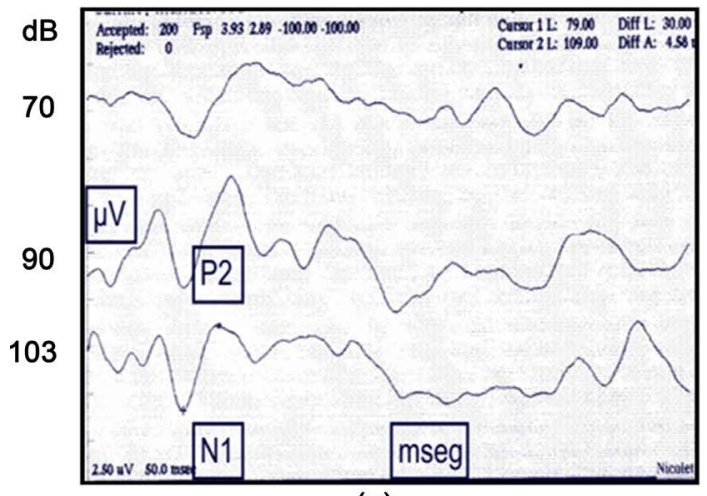

(a)

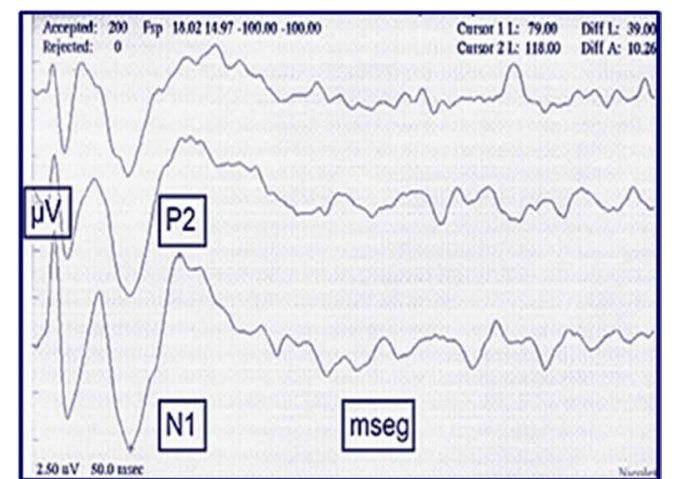

(b)

Figure 1. Illustrative examples of cortical auditory evoked potentials (200 averaged responses) obtained at stimulation of 70, 90 and $103 \mathrm{~dB}$ sound pressure level in a control woman (a) and a patient with depression (b) peak-to-peak amplitude of the N1/P2 component was measured in this study.

control subject (A) and a patient with depression (B). Latencies in milliseconds and amplitudes in $\mu \mathrm{V}$ were also calculated. The amplitude of the segment N1/P2 of the IDAEP was considered as the sum (in $\mu \mathrm{V}$ ) between the crests of the waves $\mathrm{N} 1$ and P2. The N1 component of the individual dipole source is measured as the negative peak within $60-120 \mathrm{~ms}$, and the P2 component is measured as the positive peak within 110 - 210 ms (Hegerl \& Juckel, 1993; Juckel et al., 1997, Manjarrez et al., 2001; Manjarrez et al., 2005a). Therefore, it is accepted that these components are representative of the auditory cortex integrative function (Semple \& Scott, 2003).

\section{Biochemical Assays}

Ultrafiltered plasma fractions were obtained using Nanosep $30 \mathrm{~K}$ membranes (Omega; Pall Life Science, Ann Arbor, MI) in which the FFT was measured. The high-performance liquid chromatography (HPLC) fluorescent method of Peat et al. (Peat \& Gibb, 1983) was used to quantify the FFT and the total L-Trp. The difference between these two was considered the fraction bound to albumin. Plasma albumin was determined by the method of Doumas et al. (Doumas et al., 1971). Glucose-oxidase method was use to quantify plasma glucose (Bentley, 1963), glycated hemoglobin and NAA by HPLC (Cole et al., 1978; Einarsson et al., 1983). For free fatty acid (FFA) levels assessment it was applied the Wako NEFA C test kit which uses an in vitro enzymatic colorimetric method.

\section{Statistical Methods}

Results are presented as mean \pm standard deviation. Differences between mean values were analyzed with the Student $t$-test and Levene tests with a level of significance accepted at $\mathrm{P}<0.05$. Peak-to-peak amplitude of N1/P2 component was measured at 70, 90 and $103 \mathrm{~dB}$ stimulus intensities, and the relationship between the N1/P2 component amplitude related to the auditory stimulus intensity (ASF slope) was estimated using linear regression analysis for each study group. We compared ASF slopes using Student t-test; $\mathrm{P}<0.05$ was considered significant. 


\section{Results}

A group of 60 women with an age average of $48.75 \pm 9.2$ years were studied. Patients belonged to the depressed group were significantly younger than those from the control group $(\mathrm{P}<0.001)$ and had a clinical evolution of $16 \pm 10.0$ months at the time the study was carried out. They also showed overweight $(\mathrm{P}<$ 0.05 ) and a normal level of plasma glucose. There were no changes in albumin, free fatty acids, glycosylated hemoglobin and NAA (Table 1 and Table 2). The free fraction of L-tryptophan was significantly decreased in depressed women in relation to controls $(\mathrm{P}<0.001)$. There were also no changes in the values of total L-Trp, FFT/total L-Trp and FFT/NAA (Table 3).

The most important clinical parameter studied in these patients was the intensity-dependence AEPs represented by the N1/P2 component. Notice that the ASF slope $\left(-4.76+1.28\right.$ intensity, $\left.\mathrm{r}^{2}=0.92\right)$ in the depressed patients showed a significant increase compared to controls $\left(-2.69+0.62\right.$ intensity, $\left.\mathrm{r}^{2}=0.95\right)(\mathrm{P}<$ 0.001) (Figure 2). Although there was no significant correlation observed between ASF slope and the free fraction of L-Trp (results not shown), both changes

Table 1. Clinical and biochemical data in women with depression and controls.

\begin{tabular}{ccccc}
\hline & Controls $(\mathrm{n}=30)$ & CV & Depression $(\mathrm{n}=30)$ & CV \\
\hline Age & $47.0 \pm 10.0$ & 0.21 & $41.0 \pm 8.0^{*}$ & 0.19 \\
Body mass index & $23.5 \pm 5.0$ & 0.21 & $26.9 \pm 5.0^{¥}$ & 0.18 \\
Waist circumference (cm) & $73.0 \pm 6.0$ & 0.08 & $89.8 \pm 14.0^{*}$ & 0.15 \\
Time of evolution (months) & -- & -- & $16.0 \pm 10.0$ & 0.62 \\
Beck & $3 \pm 2$ & 0.66 & $25 \pm 10.0$ & 0.40 \\
MADRS & -- & -- & $24 \pm 10.0$ & 0.41 \\
Glucose (mg/dL & $86.5 \pm 7.0$ & 0.08 & $91.3 \pm 10.0$ & 0.10 \\
Hb & & & \\
AIC $(\%)$ & $5.1 \pm 0.4$ & 0.07 & $5.5 \pm 0.6$ & 0.10 \\
Free fatty acids (mmol/L) & $0.82 \pm 0.10$ & 0.12 & $0.78 \pm 0.09$ & 0.10 \\
Albumin (g/dL) & $6.20 \pm 0.35$ & 0.5 & $6.09 \pm 0.21$ & 0.03 \\
\hline
\end{tabular}

Values are given means \pm SD. All determinations were done in duplicate sample. Differences were determined by Student’s $t$-test. ${ }^{*} \mathrm{P}<0.05, ¥<0.001 . \mathrm{CV}=$ coefficient of variation.

Table 2. Plasma concentration of neutral amino acids in women with Depression and Controls.

\begin{tabular}{ccccc}
\hline & Controls $(\mathrm{n}=30)$ & $\mathrm{CV}$ & Depression $(\mathrm{n}=30)$ & $\mathrm{CV}$ \\
\hline Valine & $327 \pm 23.5$ & 0.07 & $345 \pm 25.5$ & 0.07 \\
Isoleucine & $222 \pm 17.1$ & 0.07 & $214 \pm 14.2$ & 0.06 \\
Leucine & $346 \pm 22.8$ & 0.06 & $332 \pm 11.8$ & 0.03 \\
Phenylalanine & $187 \pm 15.0$ & 0.08 & $164 \pm 21.2$ & 0.12 \\
Tyrosine & $187 \pm 15.0$ & 0.09 & $168 \pm 14.8$ & 0.08 \\
LNAA & $187 \pm 15.0$ & 0.07 & $1223 \pm 87.5$ & 0.07 \\
\hline
\end{tabular}

Values are given as means $\pm \mathrm{SD}(\mu \mathrm{mol})$. All determinations were done in duplicate samples. Differences were determined by Student's $t$-test. $\mathrm{P}=$ Not significant. $\mathrm{CV}=$ coefficient of variation. 
Table 3. Plasma concentration of L-Tryptophan in women with Depression and Controls.

\begin{tabular}{ccccc}
\hline & Controls $(\mathrm{n}=30)$ & CV & Depression $(\mathrm{n}=30)$ & CV \\
\hline Free fraction (FFT) & $8.4 \pm 1.1$ & 0.13 & $5.9 \pm 0.9^{*}$ & 0.15 \\
Albumin bound & $31.6 \pm 5.1$ & 0.16 & $32.3 \pm 5.0$ & 0.15 \\
Total (T) & $40.0 \pm 5.3$ & 0.13 & $38.2 \pm 4.0$ & 0.10 \\
FFT/T ratio & $0.168 \pm 0.020$ & 0.11 & $0.153 \pm 0.02$ & 0.13 \\
FFT/NAA ratio & $0.006 \pm 0.001$ & 0.20 & $0.004 \pm 0.001$ & 0.20 \\
\hline
\end{tabular}

Values are given as means \pm SD $(\mu \mathrm{mol})$. All determinations were done in duplicate samples. Differences were determined by Student's $t$-test. ${ }^{*} \mathrm{P}<0.001$. CV $=$ coefficient of variation.

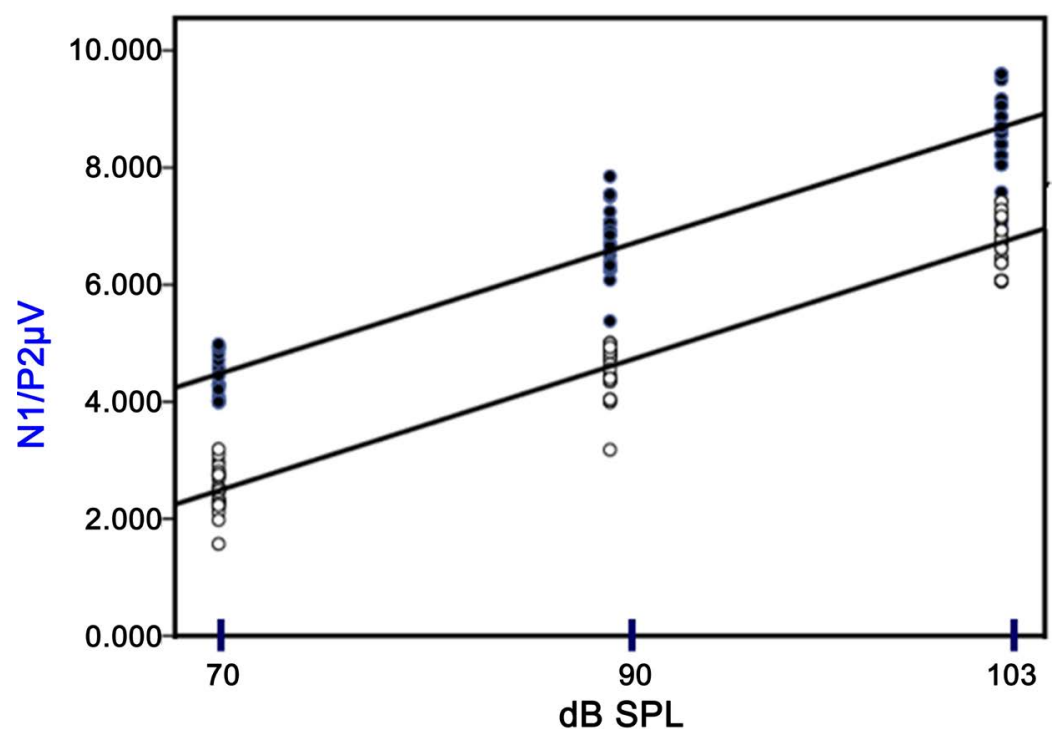

Figure 2. Multiple regression analyses and Scatter diagram. $\triangle$, Control women, ASF slope $=-2.69+0.62$ intensity, $\mathrm{r}^{2}=0.95 ; \bullet$, Depression women, ASF slope $=-4.76+1.28$ intensity, $\mathrm{r}^{2}=0.92$.

indicate low brain serotonergic tone in women with depression. Additionally, there were no changes in latencies of $\mathrm{N} 1$ and $\mathrm{P} 2$ in both groups.

\section{Discussion}

The main objective of this study was to show the decrement of serotoninergic brain activity in depressed women, through the analyses of the slope amplitude of N1/P2 components of the auditory-evoked potentials, and the measurement of the L-tryptophan free fraction in plasma. Analyses of N1/P2 components of the AEP was based on previous findings that show, this slope reflect changes in cortical activity due to abnormalities in serotonergic neurotransmission (Hegerl \& Juckel, 1993; Juckel et al., 1997; Manjarrez et al., 2001; Manjarrez et al., 2005a; Manjarrez et al., 2006; Manjarrez et al., 2007; Manjarrez-Gutierrez et al., 2009; Manjarrez-Gutierrez et al., 2013). Biochemical results showed a significantly low level of the free fraction of L-Trp in the depressed women group; fact that initially suggests a low transport of tryptophan to the brain and as a result, a low synthesis of serotonin which leads to a serotoninergic activity reduction. How- 
ever, it can also be explained by the preferential use of L-Trp by other metabolic pathways such as the kynurenic and nicotinic acid or also as a result of a hyperactivity of the hepatic tryptophan oxygenase, which catabolize the L-Trp (Badawy, 1977).

The amplitude/stimulus intensity function (ASF) of the N1/P2 component of the AEP has been proposed as an indicator of the activity of serotonergic neurons on the primary auditory cortex (Hegerl \& Juckel, 1993; Juckel et al., 1997) where a low activity of serotonergic neurons leads to a high intensity dependence with higher N1/P2 amplitudes (Manjarrez et al., 2006, Manjarrez et al., 2007; Manjarrez-Gutierrez et al., 2009; Manjarrez-Gutierrez et al., 2013).

Our results as well as those of the group of Hegerl and Juckel (Hegerl \&Juckel, 1993) strongly suggest a functional relationship between brain serotonergic activity and the N1/P2 changes to the auditory cortex responses to specific stimuli. Thus, changes in N1/P2 component of the intensity dependence of AEP, could reflect a cortical impaired activity as a result of brain serotonergic activity dysfunction. This remarkable fact is meaningful, since the component of the auditory cortex electrical activity (N1/P2) depends of the spatial and temporal integration of several neuronal processes. In fact, the electrical dipole source analyses have lead to the identification of two major components in each hemisphere (Hegerl \& Juckel 1993; Juckel et al., 1997): 1) A tangential dipole source which reflects the activation of the primary auditory cortex; and 2) A radial dipole which is results of the activity in the secondary auditory cortex. Since N1/P2 is also induced in children and detected in the corresponding auditory projections on the scalp, it seems reasonable that cortical waves reflect the integration of the auditory activity in both, children and adults (Semple \& Scott, 2003). On these bases, any dysfunction in the auditory cortex activity that lead to a change in the N1/P2 component reflects the activity of a regulatory central mechanism of sensory sensitivity. Departing from this hypothesis, a lower cortical activity would reflect a higher activity of this mechanism, triggered in order to protect the structure from sensory overload; whereas an elevation in cortical activity would be associated with a failure of the process (Ehlers et al., 1991; Von Knorring et al., 1978). Thus, in this study the increment in the ASF slope demonstrated in the group of depressed women in contrast to controls, could be the result of a detriment in the sensory cortical regulatory mechanism. As a matter of fact, a number of authors have suggested the brainstem as the source of this regulatory mechanism, which could be represented by the serotonergic system (Jacobs \& Azmitia, 1992).

Based on our biochemical and electrophysiological results, we propose that the abnormal response of the auditory cortex in the group of depressed women could be the result of a failure in serotonergic tone because of a detriment on serotonin synthesis. At the level of neurons and taking into account that this process starts at the primary auditory cortex, which owns GABAergic circuits innervated by serotonergic neurons (Jacobs \& Azmitia, 1992; Zhou \& Hablitz, 1999), the physiopathology of the failure suffered by the serotonergic tone, could 
be explained by the inhibition triggered by the GABA system. On the contrary, a reduction in GBAergic function in response to environmental stimuli could increase cortical activity, suggesting that these patients are more susceptible to auditory stimuli that may lead to behavioral changes and psychiatric disorders. On the whole, all these findings seem to be clinically relevant, since they explain metabolic and electrical changes that may play an essential role in the pathophysiology of depression. Therefore, we propose the use of the intensity dependence of AEPs (N1/P2 component) along with the measurement of plasma free fraction of L-Trp as noninvasive clinical indicators of brain serotonergic neurotransmission, methods that could be useful to differentiate depression states from a normal behavior.

\section{Acknowledgements}

The authors acknowledge the editorial support of Dr. Armando Mansilla Olivares. Luisa Cuevas is acknowledged for statistical support.

\section{Conflicts of Interest}

The authors declare no conflicts of interest.

\section{References}

Akiskal, H. S. (2000). Mood Disordes: Introduction and Overwiew. In B. J. Sadock, \& V. A. Sadock (Eds.), Comprehensive Textbook of Psychiatry (pp. 1284-1298). New York: Lippincott, Williams \& Wilkins.

American Psychiatric Association (1994). Diagnostic and Statistical Manual of Mental Disorders: DSM-IV (4th ed.). Washington DC: American Psychiatric Association.

Badawy, A. A. (1977). The Functions and Regulation of Tryptophan Pyrrolase. Life Sciences, 21, 755-768. https://doi.org/10.1016/0024-3205(77)90402-7

Banki, C. M., Molnar, G., \& Vojnik, M. (1981). Cerebrospinal Fluid Amine Metabolites, Tryptophan and Clinical Parameters in Depression: Part 2. Psychopathological Symptoms. Journal of Affective Disorders, 3, 91-99. https://doi.org/10.1016/0165-0327(81)90034-3

Bentley, R. (1963). Glucose Oxidase in the Enzymes. In P. D. Boyer (Ed.), The Enzymes (pp. 567-586). New York: Academic Press.

Berenzon, S., Lara, M. A., Robles, R. et al. (2013). Depresión: Estado del conocimiento y las necesidades políticas públicas y planes de acción en México. Salud Pública de México, 55, 74-80. https://doi.org/10.1590/S0036-36342013000100011

Berhan, A., \& Barker, A. (2014). Vortioxetine in the Treatment of Adult Patients with Major Depressive Disorder: A Meta-Analysis of Randomized Double-Blind Controlled trials. BMC Psychiatry, 14, 276. https://doi.org/10.1186/s12888-014-0276-X

Blazer, D. G. (2000). Mood Disorders: Epidemiology. In B. J. Sadoc, \& V. A. Sadock (Eds.), Comprehensive Textbook of Psychiatry (pp. 1298-1308). New York: Lippincott, Williams \& Wilkins.

Carr, G. V., \& Lucki, I. (2011). The Role of Serotonin Receptor Sybtypes in Treating Depression: A Review of Animal Studies. Psychopharmacology, 213, 265-287. https://doi.org/10.1007/s00213-010-2097-Z

Cole, R. A., Soeldner, J. S., Dunn, P. J. et al. (1978). A Rapid Method for the Determina- 
tion of Glycosylated Hemoglobin Using High-Pressure Liquid Chromatography. Metabolism, 27, 289-301. https://doi.org/10.1016/0026-0495(78)90109-9

Doumas, B. T., Watson, W. A., \& Biggs, H. G. (1971). Albumin Standards the Measurement of Serum Albumin with Bromocresol Green. Clinica Chimica Acta, 31, 87-96. https://doi.org/10.1016/0009-8981(71)90365-2

Dunlop, B. W., \& Nemeroff, C. B. (2007). The Role of Dopamine in the Pathophysiology of Depression. Archives of General Psychiatry, 64, 327-337. https://doi.org/10.1001/archpsyc.64.3.327

Ehlers, C. L., Wall, T. L., \& Chaplin, R. I. (1991). Long Latency Event-Related Potentials in Rats: Effects of Dopaminergic and Serotonergic Depletions. Pharmacology Biochemistry and Behavior, 38, 789-793. https://doi.org/10.1016/0091-3057(91)90243-U

Einarsson, S., Josefsson, B., \& Lagerkvist, S. (1983). Determination of Amino Acids with 9-Fluronylmethylcholoroformate and Reversed-Phase High-Performance Liquid Chromatography. Journal of Chromatography A, 282, 609-618. https://doi.org/10.1016/S0021-9673(00)91638-8

Ferrier, I. N., McKeith, I. G., Cross, A. J. et al. (1986). Postmortem Neurochemical Studies in Depression. Annals of the New York Academy of Sciences, 487, 128-142. https://doi.org/10.1111/j.1749-6632.1986.tb27893.x

Gijsman, H. J., Geddes, J. R., Rendell, J. M. et al. (2004). Antidepressants for Bipolar Depression: A Systematic Review of Randomized, Controlled Trials. American Journal of Psychiatry, 161, 1537-1547. https://doi.org/10.1176/appi.ajp.161.9.1537

Hegerl, U., \& Juckel, G. (1993). Intensity Dependence of Auditory Evoked Potentials as an Indicator of Central Serotonergic Neurotransmission. A New Hypothesis. Biological Psychiatry, 33, 173-187. https://doi.org/10.1016/0006-3223(93)90137-3

Jacobs, B. L., \& Azmitia, E. C. (1992). Structure and Function of the Brain Serotonin System. Physiological Reviews, 72, 165-229. https://doi.org/10.1152/physrev.1992.72.1.165

Jedynak, P., Jaholkowski, R. K., \& Filipkowski, K. R. (2007). Adult Neurogenesis and Depression. Neuropsychiatria i Neuropsychologia, 2, 57-65.

Juckel, G., Molnár, M., Hegerl, U. et al. (1997). Auditory-Evoked Potentials as Indicator of Brain Serotonergic Activity-First Evidence in Behaving Cats. Biological Psychiatry, 41, 1181-1195. https://doi.org/10.1016/S0006-3223(96)00240-5

Kessler, R. C., \& Bromet, E. J. (2013). The Epidemiology of Depression across Cultures. Annual Review of Public Health, 34, 119-138. https://doi.org/10.1146/annurev-publhealth-031912-114409

Lohoff, F. W. (2010). Overview of the Genetics of Major Depressive Disorder. Current Psychiatry Reports, 12, 539-546. https://doi.org/10.1007/s11920-010-0150-6

López, J. F., Chalmers, D. T., Little, K. Y. et al. (1998). A.E. Bennett Research Award. Regulation of Serotonin 1A, Glucocorticoid, and Mineralocorticoid Receptor in Rat and Human Hippocampus: Implications for the Neurobiology of Depression. Biological Psychiatry, 43, 547-573. https://doi.org/10.1016/S0006-3223(97)00484-8

Manjarrez, G., Cisneros, I., Herrera, R. et al. (2005a). Prenatal Impairment of Brain Serotonergic Transmission in Infants. The Journal of Pediatrics, 147, 592-596. https://doi.org/10.1016/j.jpeds.2005.06.025

Manjarrez, G., Hernandez, E., Robles, A. et al. (2005b). N1/P2 Component of Auditory Evoked Potential Reflect Changes of the Brain Serotonin Biosynthesis in Rats. Nutritional Neuroscience, 8, 213-218. https://doi.org/10.1080/10284150500170971

Manjarrez, G., Hernandez, Z. E., Robles, O. A. et al. (2001). Developmental Impairment of Auditory Evoked N1/P2 Component in Rats Undernourished in Utero: Its Relation 
to Brain Serotonin Activity. Brain Research. Developmental Brain Research, 127, 149-155. https://doi.org/10.1016/S0165-3806(01)00129-8

Manjarrez, G., Herrera, R., León, M. et al. (2006). A Low Brain Serotonergic Neurotransmission in Children with Type 1 Diabetes Detected through the Intensity Dependence of Auditory Evoked Potentials. Diabetes Care, 29, 73-77. https://doi.org/10.2337/diacare.29.01.06.dc05-1177

Manjarrez, G., Vazquez, F., Delgado, M. et al. (2007). A Functional Disturbance in the Auditory Cortex Related to a Low Serotonergic Neurotransmission in Women with Type 2 Diabetes. Neuroendocrinology, 86, 289-294. https://doi.org/10.1159/000109375

Manjarrez-Gutierrez, G., Herrera, R. H., Mejenes-Alavarez, S. A. et al. (2009). Functional Change of the Auditory Cortex Related to the Brain Serotonergic Neurotransmission in Type 1 Diabetic Adolescents with and without Depression. The World Journal of Biological Psychiatry, 10, 877-883. https://doi.org/10.1080/15622970902717032

Manjarrez-Gutierrez, G., Ramirez-Campillo, R., Borrayo-Sanchez, G. et al. (2013). Disturbance of Serotonergic Neurotransmission in Patients with Postmyocardial Infarction and Depression. Metabolic Brain Disease, 28, 15-20.

https://doi.org/10.1007/s11011-012-9355-1

Mann, J. J. (1999). Role of the Serotonergic System in the Pathogenesis of Major Depression and Suicidal Behavior. Neuropsychopharmacology, 21, 99S-105S.

https://doi.org/10.1016/S0893-133X(99)00040-8

Margoob, M. A., Mushtaq, D., Murtza, I. et al. (2008). Serotonin Transporter Gene Polymorphism and Treatment Response to Serotonin Reuptake Inhibitor (Escitalopram) in Depression. An Open Pilot Study. Indian Journal of Psychiatry, 50, 47-50. https://doi.org/10.4103/0019-5545.39759

McNally, L., Bhagwagar, Z., \& Hannestad, J. (2008). Inflammation, Glutamate, and Glia in Depression. A Literature Review. CNS Spectrums, 13, 501-510. https://doi.org/10.1017/S1092852900016734

Medina-Mora, M. E., Borges, G., Lara, C. et al. (2005). Prevalence, Service Use, and Demographic Correlates of 12-Month DSM-IV Psychiatric Disorders in Mexico: Results from the Mexican National Comorbidity Survey. Psychological Medicine, 35, 1773-1783. https://doi.org/10.1017/S0033291705005672

Meltzer, H. Y. (1990). Role of Serotonin in Depression. Annals of the New York Academy of Sciences, 600, 486-499. https://doi.org/10.1111/j.1749-6632.1990.tb16904.x

Morrissette, D. A., \& Stahl, S. M. (2014). Modulating the Serotonin System in the Treatment of Major Depressive Disorder. CNS Spectrums, 1, 57-67. https://doi.org/10.1017/S1092852914000613

Nagayama, H., Tsuchiyama, K., Yamada, K. et al. (1991). Animal Study on the Role of Serotonin in Depression. Progress in Neuro-Psychopharmacology \& Biological Psychiatry, 15, 735-744. https://doi.org/10.1016/0278-5846(91)90002-I

Nestler, E. J., Barrot, M., DiLeone, R. J. et al. (2002). Neurobiology of Depression. Neuron, 34, 13-25. https://doi.org/10.1016/S0896-6273(02)00653-0

Nutt, D. J. (2006). The Role of Dopamine and Norepinephrine in Depression and Antidepressant Treatment. Journal of Clinical Psychiatry, 67, 3-8.

Parker, K. J., Schatzberg, A. F., \& Lyons, D. M. (2003). Neuroendocrine Aspects of Hypercortisolism in Major Depression. Hormones and Behavior, 43, 60-66. https://doi.org/10.1016/S0018-506X(02)00016-8

Patel, A. (2013). Review: The Role of Inflammation in Depression. Psychiatria Danubina, 2, S216-S223. 
Peat, M. A., \& Gibb, J. W. (1983). High-Performance Liquid Chromatography Determination of Indoleamines, Dopamine, and Norepinephrine in Rat Brain with Fluorometric Detection. Analytical Biochemistry, 128, 275-280. https://doi.org/10.1016/0003-2697(83)90375-5

Pehrson, A. L., \& Sanchez, C. (2014). Serotonergic Modulation of Glutamate Neurotransmission as a Strategy for Treating Depression and Cognitive Dysfunction. CNS Spectrums, 19, 121-133. https://doi.org/10.1017/S1092852913000540

Semple, M. N., \& Scott, B. H. (2003). Cortical Mechanism in Hearing. Current Opinion in Neurobiology, 13, 167-173. https://doi.org/10.1016/S0959-4388(03)00048-5

Stanley, M., Traskman-Bendz, L., \& Dorovini-Zis, K. (1985). Correlations between Aminergic Metabolites Simultaneously Obtained from Human CFS and Brain. Life Sciences, 37, 1279-1286. https://doi.org/10.1016/0024-3205(85)90242-5

Stockmeier, C. A., Dailley, G. E., Shapiro, L. A. et al. (1997). Serotonin Receptor in Suicide Victims with Major Depression. Neuropsychopharmacology, 16, 162-173. https://doi.org/10.1016/S0893-133X(96)00170-4

Sullivan, P. F., Neale, M. C., \& Kendler, K. S. (2000). Genetic Epidemiology of Major Depression: Review and Meta-Analysis. American Journal of Psychiatry, 157, 1552-1562. https://doi.org/10.1176/appi.ajp.157.10.1552

Von Knorring, L., Monakhov, K., \& Perris, C. (1978). Augmenting/Reducing: An Adaptive Switch Mechanism to Cope with Incoming Signals in Healthy Subjects and Psychiatric Patients. Neuropsychobiology, 4, 150-179. https://doi.org/10.1159/000117630

Wagner, A. F., González, F. C., Sánchez, G. S. et al. (2012). Enfocando la depresión como problema de salud pública en México. La Salud Mental, 35, 3-11.

Zhou, F., \& Hablitz, J. J. (1999). Activation of Serotonin Receptors Modulates Synaptic Transmission in Rat Cerebral Cortex. Journal of Neurophysiology, 82, 2989-2999. https://doi.org/10.1152/jn.1999.82.6.2989 